\title{
AS WEBSÉRIES ENQUANTO CAMPO DE ESTUDO DA NARRATOLOGIA
}

\author{
JOÃO PAULO HERGESEL \\ UNIVERSIDADE DE SOROCABA \\ SOROCABA, SÃO PAULO, BRASIL \\ J.HERGESEL@EDU.UNISO.BR
}

HTTP://DX.DOI.ORG/10.5902/2316882X16241 


\section{AS WEBSÉRIES ENQUANTO CAMPO DE ESTUDO DA NARRATOLO- $\mathrm{GIA}^{1}$}

Resumo: Neste artigo, pretendeu-se discutir a websérie como narrativa midiática e ressaltar a possibilidade de transformação do signo prosaico em comunicação passível de suscetibilidade. Para que isso ocorresse, fez-se uma revisão teórica do histórico das webséries e das categorias da narrativa e, posteriormente, uma discussão do conceito de narrativa midiática embasado pela Comunicação e pela Cultura.

Palavras-chave: Comunicação e Linguagem. Linguística Textual. Narrativas midiáticas. Webséries.

\section{LAS SERIES WEB COMO UN CAMPO DE ESTUDIO DE LA NARRATO- LOGÍA}

Resumen: En este trabajo se pretendió discutir las series web como narrativa en media y hacer hincapié en la posibilidad de transformar el signo prosaico en comunicación susceptible. Para que eso tuviera éxito se hizo una revisión teórica de la historia de las series web y de las categorías narrativas y luego una discusión sobre el concepto de narrativa en media con base en la Comunicación y en la Cultura.

Palabras clave: Comunicación y Lenguaje. Lenguaje Textual. Narrativas en media. Series web.

\section{THE WEB SERIES AS A FIELD OF STUDY IN NARRATOLOGY}

Abstract: In this paper, it was intended to discuss web series as media narrative and to emphasize the possibilities of transformation from the prosaic sign into susceptible communication. For that, it was made a theoretical review of the web series' history and the categories of narrative, and then, a discussion about the concept on media narrative, grounded for Communication and Culture.

Keywords: Communication and Language. Textual Linguistics. Media Narratives. Web series.

1 Versão recortada, revista e atualizada da Dissertação de Mestrado Considerações estilísticas sobre webséries brasileiras: a narrativa midiática no contexto do universo on-line, defendida em 31 de outubro de 2014, no Programa de Pós-Graduação em Comunicação e Cultura da Universidade de Sorocaba.

Rev.Cad.Comun. Santa Maria, v.20, n.3, art 7, p.148 de 159, set/dez.2016 


\section{Webséries, um objeto de interesse da narratologia}

O estudo das narrativas recebe o nome de Narratologia (TODOROV, 1982). Pesquisas neste campo são vistas como fundamentais para a Comunicação e para a Cultura: para esta, pois a narrativa surgiu na oralidade, nas aventuras relatadas por marujos e nos costumes sustentados por camponeses (BENJAMIN, 1994) e se manteve através dos anos, atingindo a hipermídia (GOSCIOLA, 2008); para aquela, pois estabelece uma relação midiática entre os vínculos sociais e possibilita a manifestação dos sujeitos (LEAL, 2006).

Sustentou-se, aqui, como significado de Cultura, o conjunto de informações que, embora não sejam hereditárias, os seres humanos, em seus coletivos sociais, são responsáveis por acumular, conservar e transmitir (LOTMAN, 1979a). Em outras palavras, a cultura, sendo memória não genética, é um texto amplo o suficiente para abranger outros textos dentro de si, e a interação entre esses textos resulta em um sistema sígnico (SILVA, 2010).

Como definição de Comunicação, adotou-se a ideia de França (2001, p. 1), de que a área compreende o processo de "produção e compartilhamento de sentidos entre sujeitos interlocutores" quando este é realizado por meio "de uma materialidade simbólica - da produção de discursos e inserido em determinado contexto sobre o qual atua e do qual recebe os reflexos". Para além dessa abordagem, considerou-se o consumidor da narrativa, por meio de sua leitura e interpretação, um colaborador para a recriação do texto (WOLFF, 1982).

É sabido também que texto, o significado da palavra, não se restringe aos limites da linguagem verbal, podendo-se estender ao sonoro, ao imagético, ao audiovisual e a outras tantas formas de expressão (GUIMARÃES, 2004). E, por ser fruto da expressão linguística, é capaz de transferir para algum tipo de mídia - e aqui, entendemos como mídia o meio, a ponte, pelo qual dois corpos fazem contato (BAITELLO JUNIOR, 2012) - o cerne de reflexões pessoais, sentimentos, ideias, características afetivas e intelectuais (BALLY, 1909).

Dentre as superestruturas textuais, ou seja, a estrutura generalizada que caracteriza um tipo de texto sem necessariamente levar em consideração seu conteúdo, encontra-se a narrativa (GUIMARÃES, 2004). Em outras palavras, configura-se como narrativo qualquer texto composto 
pelos seguintes elementos básicos: foco narrativo, ação, personagem, espaço e tempo (VASCONCELOS, 2008). Assim, torna-se necessário que o autor crie uma sensação de objetividade apoiada na temporalidade, materializando uma sequência de eventos e, posteriormente, transformando tais ocorrências relatadas (ABDALA JUNIOR, 1995).

Com base nesses pensamentos e sustentados pelas explanações de Silva (2010), estabeleceu-se uma forte relação entre Narratologia, Comunicação e Cultura: texto narrativo pode configurar-se como um exemplo de texto artístico; texto artístico é sinônimo de signo poético e, portanto, um tipo de linguagem; linguagem é, sobretudo, cultura; e é na cultura (por ela e com ela) que ocorre a comunicação.

Partindo dessa lógica, investigamos por que o formato websérie se caracteriza como texto narrativo e o que faz com que ele seja um objeto de interesse da Narratologia. Para tanto, realizamos uma revisão bibliográfica do histórico e das categorias da narrativa, discutindo sua conceptualização.

\section{A websérie como narrativa midiática}

A narrativa é uma das mais antigas mídias. Embora, para Benjamin (1994), ela tenha surgido nas histórias contadas pelos navegadores, exploradores em alto-mar, e na tradição a ser mantida pelos campesinos, sabemos que essa ideia é válida apenas para a expressividade oral. A narrativa, como forma de comunicação, está presente, desde sempre no dia a dia. Com Bretas (2006), narrar foi a maneira encontrada pelo homem para poetizar a teatralidade prosaica do cotidiano.

Quando o morador das cavernas aprendeu a se comunicar e registrou, nas rochas, por meio de desenhos rupestres, o que via, caçava ou pretendia, para que outro fizesse uma leitura visual das imagens e compreendesse o que se passava, constituía-se uma narrativa. Obviamente, a narrativa não estava presente na escrita, nem na oralidade, mas se manifestava por meio do texto não verbal.

Presente em vários tipos de linguagem, a narrativa passou pela oralidade (contação de história) pela escrita (literatura), pelas imagens (pinturas, fotografias), pelo audiovisual (cinema, televisão) e alcançou a hipermídia. Dada a consolidação do espaço cibernético e da facilidade de interação entre os usuários desse meio, as narrativas se expandiram em

Rev.Cad.Comun. Santa Maria, v.20, n.3, art 7, p.150 de 159, set/dez.2016 
narrativa transmídia, quando o conteúdo de uma mídia se apropria de outra mídia alternativa, e em narrativa de hipermídia, isto é, "o conjunto de meios que permite acesso simultâneo a textos, imagens e sons de modo interativo e não linear, possibilitando fazer links entre os elementos de mídia, controlar a própria navegação" (GOSCIOLA, 2008, p. 34-35).

Acredita-se que um exemplo contemporâneo de narrativa é a websérie. Idealizada em 1988, com o projeto The QuantumLink Serial ${ }^{2}-$

[...] muito antes de a Internet mudar a maneira como as pessoas vivem suas vidas cotidianas, havia uma forma inovadora de contar histórias chamado The QuantumLink Serial, na AOL. Idealizado pelo escritor Tracy Reed em 1988, o mundo experimentou pela primeira vez a série on-line de ficção, via sala de chat, e-mail e narrativa tradicional. Também foi interativa, já que Reed muitas vezes incorporou material inspirado pelos fãs. Depois de seu fim, em 1989, a web não hospedou nada assim por um bom tempo (DUNLOP, 2014, p. 1)3.

- e concretizada em 1995, com o projeto The Spot (cf. THE SPOT, 1995) -

Em 1995, um homem chamado Scott Zakarin concebeu e criou a (websérie) The Spot, que contou com um elenco de vinte e poucos anos vivendo em Santa Monica. Os personagens, conhecidos como Spotmates, compartilhavam (pré-LiveJournal) atualizações de status quase em uma base diária. Muito parecido com The Serial QuantumLink, os fãs foram capazes de alterar storylines, enviando e-mails para os personagens, que respondiam de volta, graças a uma equipe de roteiristas liderada por Zakarin. Com o vício do fundador-anunciante, o mundo teve a sua primeira websérie. Embora tendo atingido rapidamente picos de mais de 100.000 acessos diários, a ficção por trás da verossimilhança diluiu a indústria e levou sua companhia de pro-

2 Não foram encontradas referências para acesso a esta websérie. Há a suposição, portanto, de que ela não é mais armazenada por nenhum website.

3 Tradução livre do inglês. Fragmento original: "Once upon a time, long before the Internet changed the way people live their everyday lives, there was a groundbreaking form of storytelling called 'The QuantumLink Serial' on AOL. Masterminded by writer Tracy Reed in 1988, the world would experience the first-ever online fictional series via chat room, email and traditional narrative. It would also be interactive, as Reed would oftentimes incorporate material inspired by fans. After its end in 1989, the web would not host anything like this for quite awhile."

Rev.Cad.Comun. Santa Maria, v.20, n.3, art 7, p.151 de 159, set/dez.2016 
-, a websérie é um texto narrativo em linguagem audiovisual dividida em episódios e feita para circular em meio cibernético. Espelha-se muito nas séries de televisão, embora apresentem baixo orçamento (pela dificuldade em conquistar patrocinadores), episódios mais curtos e temporadas menores (AERAPHE, 2013).

A websérie, portanto, é uma narrativa audiovisual seriada em difusão na hipermídia; há a possibilidade de identificá-la como narrativa hipermidiática, pois "está mais para um produto com um nível de navegabilidade, de interatividade e de volume de documentos maior do que a multimídia e com mais intensidade em conteúdos audiovisuais do que o hipertexto" (GOSCIOLA, 2008, p. 34), dado que ela se completa com a interação de hiperlinks, cria hiperlinks para vídeos relacionados e páginas afins e ainda permite o relacionamento entre autor/leitor.

Por outro lado, há estudos que a enxergam como uma narrativa transmídia, como os compilados por Aeraphe (2013), visto que ela se desloca para diferentes espaços: muitas surgem na televisão e, para manter o público, estendem-se até a internet; outras, mais raramente, fazem o processo inverso e saem da internet para a televisão. Além do mais, podem estar presentes em redes sociais e websites distintos da ferramenta armazenadora de vídeos e se derivar em outras mídias: livros, DVDs, vlogs, HQs, etc.

Seria possível, também, pensar na hipótese de categorizá-la como uma narrativa crossmídia, posto que ela possui um modelo de distribuição que se complementa com diversas plataformas, conforme Ellingsen (2012). A narrativa webserializada também acontece, por exemplo, nas redes sociais, nos blogs, nos websites, nos serviços armazenadores de vídeos e em outras possíveis mídias simultaneamente.

4 Tradução livre do inglês. Fragmento original: "In 1995, a man named Scott Zakarin would conceive and create the "The Spot," which featured a cast of twenty-somethings living in Santa Monica. The characters, known as "Spotmates," would share (pre-LiveJournal) diary entries almost on a daily basis. Much like "The QuantumLink Serial," fans were able to alter storylines by sending emails to the characters who would reply back thanks to a Zakarin-led writing team. With the addition of advertiser-funded video, the world had its very first web series. Although it peaked quickly with numerous $100,000+$ hit days, phony versions of this soap would dilute the industry and force its production company into bankruptcy by 1997." 
Por fim, também torna-se aceitável enquadrá-la no conceito de multimídia - com Prado (2010), o conjunto de textos estáticos e/ou dinâmicos que podem ser acessados pelo leitor de diferentes maneiras -, visto que o leitor tem a liberdade de navegar de forma não linear, escolhendo qual episódio quer assistir, optar por deixar a playlist no modo aleatório ou por fazer pausas e pular partes do vídeo, muitas vezes sem que isso comprometa a narrativa.

Contudo, ainda que crentes na relevância de uma definição, é notável a complexidade do objeto e o fato de ele ainda estar compondo sua identidade; portanto, não houve preocupação, aqui, por classificar a websérie como narrativa hipermidiática, ou transmídia, ou crossmídia, ou multimídia. Denominou-se apenas narrativa midiática e ocupou-se, somente, em discuti-la como objeto de interesse da Narratologia e em investigar sua contribuição para a Comunicação e para a Cultura.

A primeira contribuição é que, diferente de outros produtos audiovisuais, como a maioria das séries de televisão, a websérie não tem a obrigação de ser comercial - podendo vir a ser, dependendo da circunstância -, mas a de servir como um mecanismo para experimentar recursos artísticos (LOPEZ MERA, 2010). Ao apropriar-se, portanto, da relação entre arte e narrativa (cf. LOTMAN, 1978), pode-se considerar a websérie como uma possibilidade de texto artístico. Justifica-se:

\begin{abstract}
Junto da fácil acessibilidade e usabilidade de novas tecnologias, também surge a necessidade de utilizá-las para a experimentação artística. Esse é o caso das webséries, uma novidade embasada nas séries de televisão que busca seu lugar no campo da arte e do entretenimento. [...] É difícil conseguir com que uma rede de televisão invista em obras audiovisuais experimentais; no entanto, a internet, por não estar submetida às restrições impostas pelas grandes massas, permite que realizadores, tanto amadores como profissionais, façam experimentações com webséries. (LOPEZ MERA, 2010, pp. 1-4).
\end{abstract}

Parafraseando Todorov (1971), o texto artístico pode ser o ponto definitivamente final de uma obra ou a manifestação de outro fenômeno. No primeiro caso, não pode ser considerado nem como manifestação inconsciente ou concepção filosófica, e sim como um discurso que se faz conhecer por si mesmo. Dessa forma, o que se investiga são as peculiaridades nas relações que entretêm seus constituintes ou com outras obras. 
Ainda nesse pensamento, o que se busca por meio de uma análise não são as causas para as ações apresentadas, e sim as razões que visam a justificar a existência de um fenômeno. No entanto, a descrição de uma obra por si própria é tida como algo improvável (e, se possível, descartável), dado que ela constitui, dentro dela mesma, sua melhor forma de se descrever.

O objetivo de descrever um texto é que se permaneça tão próximo quanto possível da respectiva obra, sem devaneios, nem aprofundamento linguístico ou interpretativo; ou seja, é um resumo geral e, ao mesmo tempo, uma explicitação geralmente rasa do assunto abordado. Por isso, consideramos que a descrição não pode satisfazer a ciência.

Decidiu-se, portanto, seguir pelo caminho da segunda definição, ou seja, da manifestação de outro produto, que, para Todorov (1971), é o que mais se aproxima do saber científico, visto que a ideia é partir da obra para chegar a estruturas. É uma visão correlacionada aos estudos psicanalíticos e psicológicos, etnológicos e sociológicos, criados com vínculo na História e na Filosofia.

Essa forma de estudo, denominada estudo de transição, tem como objetivo a transposição da obra para outro discurso, considerado por Todorov (1971) como fundamental: um trabalho que consiste em decifrar e traduzir. Ainda para o autor, as propriedades do discurso compõem o objeto da poética estrutural e, se as análises forem convincentes, passam a fazer parte da ciência.

\section{Websérie, narrativa, arte e tecnologia}

Na visão de Tinianov (apud LOTMAN, 1979b), a obra artística não é um aglomerado de informações simétricas fechado, mas uma totalidade dinâmica e desenvolvível. Em acréscimo a essa hipótese, nas palavras de Lotman (1979b, p. 132-133), "a estrutura dinâmica será construída com uma certa quantidade de modelos estáticos que estão numa determinada relação móvel". Isto é, a junção de diversos elementos estáticos forma uma produção dinâmica. A descrição estática, portanto, é o primeiro passo para que se possa atingir as construções dinâmicas.

Além disso, uma narrativa geralmente tem um ponto de vista autoral e um do leitor, por meio dos quais os acontecimentos são notados. Quando criada, a visão narrativa não se concentra na perspectiva verdadeira do 
espectador, pois esta é variável, dependendo dos fatores externos à obra; segue-se a perspectiva de um espectador virtual, ou seja, o idealizado, o esperado, o abstrato - um narratário (TODOROV, 1971).

A apresentação abstrata de um texto concreto se dá por um processo triplo: uma especificação sintática - como ocorre o encadeamento das proposições, ou seja, das ações que constituem uma unidade mínima -, uma interpretação semântica - em que cada elemento pode ser avaliado em seu grau mais alto e em diversos níveis - e uma representação verbal - o porquê das palavras escolhidas. A representação verbal coincide com a interpretação semântica que, por sua vez, está integralmente ligada à especificação sintática. Em outras palavras, o produto final da narrativa se faz na linguagem.

Todorov (1971) também ensina que a análise estrutural da narrativa se dá em três ordens: lógica, temporal e espacial. A ordem lógica busca identificar a causalidade, seja a dos acontecimentos (cuja ênfase recai sobre as ações, as quais são obrigatoriamente provocadas por ações precedentes), a psicológica (que não derivam de outra ação, mas sim de um traço de caráter do narrador ou do personagem) ou a filosófica (a qual compreende como ação o simbolismo das ideias que se formam com o desenvolvimento da história).

Uma descrição das causas e consequências responsáveis pela movimentação da narrativa visam ao rompimento daquilo que se encontra implícito, isto é, faz com que o leitor interaja com a obra e procure interpretar o que o narrador se recusou a dizer. A causa, por sua vez, é apresentada como fator ligado à temporalidade e só pode ocorrer em narrativas cronológicas. Para o autor (TODOROV, 1971), quando há apenas causalidade, ocorre uma intriga; mas quando está vinculada à temporalidade, nasce uma narrativa.

Partindo dessa perspectiva temporal da narrativa, tem-se a arte e a linguagem umbilicadas: o texto artístico torna-se um produto composto por um sistema de signos que busca, de alguma forma, estabilizar-se. 0 artista, ou produtor, ao organizar esses signos, cria um conteúdo apoiado em seu estilo; o espectador, ou consumidor, acrescenta seu conteúdo próprio, que coincide parcialmente com o conteúdo do produtor ou de outro consumidor (USPENSKII, 1981).

A websérie, portanto, pode vir a ser um exemplo de obra artística, quando composta por uma complexidade de signos poéticos - ideia enga- 
jada em Lopez Mera (2010, p. 4), “a websérie é arte e tecnologia”. O que difere a websérie de outras obras de arte, como a pintura ou a literatura, é que sua reprodução não movimenta pensamentos a respeito de uma possível inferioridade de valor; ao contrário, ela precisa ser veiculada em vários espaços da hipermídia para ser reconhecida. Conforme Benjamin (1955), a reprodutibilidade da obra de arte permite a conquista de um espaço próprio entre os procedimentos artísticos, tal qual o cinema.

Inspirado por Benjamin, a fala do professor doutor Maurício Reinaldo Gonçalves (informação verbal)5 deixa claro que "a própria possibilidade de reprodutibilidade técnica instaura uma nova expressividade de experimentação artística", o que faz com que não exista original no cinema: "O cinema, como expressão artística (ou não), só se faz presente na reprodução." Por fim, enfatiza que "a cópia é quase fundamental para a existência do cinema". Visto que o cinema é um dos pontos de origem da websérie, adota-se, aqui, esse conceito.

\section{Considerações}

Com tudo o que se apresentou nesse discorrimento, entende-se a websérie como uma narrativa midiática e, dependendo do caso, como um texto artístico; em consequência, é possível tê-la também como pertencente à Comunicação, por estabelecer um vínculo entre o sujeito e seus interlocutores, e à Cultura, por utilizar informações acumuladas, conservadas e transmitidas dentro de um contexto social.

Considera-se, portanto, a websérie como uma narrativa audiovisual dividida em episódios e veiculada no espaço cibernético, visto que tal formato contém os elementos necessários para a construção de um texto narrativo midiático: enredo, personagens, ambientação, temporalidade, foco narrativo e discurso. Julga-se ainda que pesquisas com esse enfoque contribuem significativamente para a área de Comunicação e Cultura, posto que, como produto midiático, a websérie estabelece uma relação entre produtor e consumidor por meio de uma criação cultural em ascensão.

$5 \quad$ Fala do professor Dr. Maurício Reinaldo Gonçalves, no encontro de 30 de setembro de 2013 do Grupo de Pesquisa em Narrativas Midiáticas (Nami), da Universidade de Sorocaba (Uniso).

Rev.Cad.Comun. Santa Maria, v.20, n.3, art 7, p.156 de 159, set/dez.2016 
CADERNOS DE COMUNICAÇÃO

UNIVERSIDADE FEDERAL DE SANTA MARIA

REFERÊNCIAS

ABDALLA JUNIOR, Benjamin. Introdução à análise da narrativa. São Paulo: Scipione, 1995 - Coleção Margens do Texto.

AERAPHE, Guto. Webséries: criação e desenvolvimento. Belo Horizonte: [edição do autor], 2013.

BAITELLO JUNIOR, Norval. O que são meios, ou seja, o que é a mídia? In: .0 pensamento sentado: sobre glúteos, cadeiras e imagens. São Leopoldo: Unisinos, 2012, p. 60.

BALLY, Charles. Traité de stylistique française: premier volume. Paris: Libraire C. Klincksieck, 1909.

BRETAS, Beatriz. Interações cotidianas. In: FRANÇA, Vera; GUIMARÃES, César. Na mídia, na rua: narrativas do cotidiano. Belo Horizonte: Autêntica, 2006, p. 29.42.

BENJAMIN, Walter. O narrador: considerações sobre a obra de Nikolai Leskov. In: - Magia e técnica, arte e política: ensaios sobre literatura e história da cultura. São Paulo: Brasiliense, 1994, p. 197-221.

DUNLOP, Ricky. Evolution of the Web Series. The Blot Magazine. 24 abr. 2014. Disponível em: <http://theblot.com/evolution-web-series-first-one-1988-7718343>. Acesso em: 29 jul. 2014 .

ELLINGSEN, Steinar. A book chapter on web series networks for "Crossmedia Innovations" - Web series networks: How independent media are pushing the boundaries of emerging genres (suggested chapter title). 2012. Disponível em: <http://steinarellingsen. com/2012/03/03/a-book-chapter-on-web-series-networks-for-crossmedia-innovations/> Acesso em: 14 out. 2013.

FRANÇA, Vera. Paradigmas da Comunicação: conhecer o quê? Ciberlegenda, n. 5, 2001. Disponível em: <http://www.uff.br/mestcii/era1.htm>. Acesso em: 04 set. 2013.

FRANÇA, Vera. Sujeito da comunicação, sujeitos em comunicação. In: FRANÇA, Vera; GUIMARÃES, César. Na mídia, na rua: narrativas do cotidiano. Belo Horizonte: Autêntica, 2006, p. 61-88.

LEAL, Bruno. Saber das narrativas: narrar. In: FRANÇA, Vera; GUIMARÃES, César. Na mídia, na rua: narrativas do cotidiano. Belo Horizonte: Autêntica, 2006, p. 19-27.

LOPEZ MERA, Diego Darío. WEBSERIES: Nuevo fenómeno de experimentación audiovisual y entretenimento. 2010. Disponível em: <http://issuu.com/diegodario/docs/webse-

Rev.Cad.Comun. Santa Maria, v.20, n.3, art 7, p.157 de 159, set/dez.2016 
ries>. Acesso em: 23 jun. 2012.

LOTMAN, luri. A estrutura do texto artístico. Dissertação de Mestrado apresentada junto ao Departamento de Linguística e Línguas Orientais. Faculdade de Filosofia, Letras e Ciências Humanas da Universidade de São Paulo. USP: São Paulo, 1978.

. Sobre o problema da tipologia da cultura. In: SCHNAIDERMAN, Boris. Semiótica russa. São Paulo: Perspectiva, 1979a, p. 31-41.

. Sobre algumas dificuldades de princípio na descrição estrutural de um texto. In: SCHNAIDERMAN, Boris. Semiótica russa. São Paulo: Perspectiva, 1979b, p. 131-138.

GOSCIOLA, Vicente. Roteiro para as novas mídias: do cinema às mídias interativas. São Paulo: Editora Senac São Paulo, 2008.

GUIMARÃES, Elisa. A articulação do texto. São Paulo: Ática, 2004.

PRADO, José Luiz Aidar. Crítica dos media em narrativas hipermidiáticas. Brazilian Journalism Research, Brasília, DF, v. 6, n. 1, 2010, pp. 150-163.

SILVA, Míriam Cristina Carlos. Contribuições de luri Lotman para a comunicação: sobre a complexidade do signo poético. In: FERREIRA, Giovandro Marcus et. al. Teorias da comunicação: trajetórias investigativas. Porto Alegre: EdiPUCRS, 2010, p. 273-291.

THE SPOT (1995-1997). Direção de Scott Zakarin. Estados Unidos: Fattal \& Collins; American Cybercast, 1995-1997. Disponível em: <http://thespot.com/>. Acesso em: 29 jul. 2014.

TODOROV, Tzvetan. A gramática do Decameron. São Paulo: Perspectiva, 1982.

. As categorias da narrativa literária. In: BARTHES, Roland; GREIMAS, A. J.; BREMOND, Claude et al. Análise estrutural da narrativa. Petrópolis: Vozes, 1971, p. 209254.

. As estruturas narrativas. São Paulo: Perspectiva, 2006.

VASCONCELOS, José Paulo. Categorias da Narrativa. Escola Secundária Santa Maria do Olival. 03/06/2008. Disponível em: <http://jpvasc.no.sapo.pt/port-10/narrativa.pdf>. Acesso em: 01 set. 2013.

WOLFF, Janet. A interpretação como recriação. In: arte. Rio de Janeiro: Zahar, 1982. . A produção social da 


\title{
Resumo sobre autor:
}

\begin{abstract}
João Paulo Hergesel
Mestre em Comunicação e Cultura e licenciado em Letras pela Universidade de Sorocaba. Membro do Grupo de Pesquisa em Narrativas Midiáticas (Nami), docente do Colégio Objetivo São Roque e administrador da Editora Jogo de Palavras. Dedica-se à produção literária e à pesquisa na área de Narrativas Midiáticas, com enfoque no estudo do estilo. Contato: j.hergesel@edu.uniso.br.
\end{abstract}

RECEBIDO EM: 20/03/2016

ACEITO EM: 01/09/2016 